\title{
O acolhimento do imigrante como marco de solidariedade no contexto de graduação em Saúde
}

\author{
The reception of immigrants as a mark of solidarity in the \\ context of undergraduate courses in Health \\ LUIZ CLAUdio SOBRINHO do NASCIMENTOa \\ CESAR KUZMA ${ }^{b}$ \\ MARIA CeCílIA Da LOZZO GARBELINI ${ }^{c}$ \\ MARIA ROSA MACHADO ${ }^{d}$ \\ LEIDE DA CONCEIÇÃO SANCHES ${ }^{\mathrm{e}}$
}

\section{Resumo}

A imigração é um fenômeno que traz desafios, tanto para os imigrantes quanto para as sociedades que os acolhem. Este estudo teve como objetivo perceber como o acolhimento dos imigrantes é trabalhado nos cursos de graduação em saúde, pela perspectiva dos discentes. Trata-se de um estudo exploratório descritivo com abordagem qualitativa, no qual foram realizadas entrevistas semiestruturadas com vinte e oito (28) discentes de três (3) cursos de graduação em saúde de duas Instituições de Ensino Superior (IES) da cidade de Curitiba/PR. As informações foram analisadas

\footnotetext{
a Universidade Positivo (UP), Curitiba, PR, Brasil. Mestre em Ensino nas Ciências da Saúde, e-mail: luinascimento73@gmail.com

b Pontifícia Universidade Católica do Rio de Janeiro (PUCRJ), Rio de Janeiro, RJ, Brasil. Doutor em Teologia, e-mail: cezarkusma@gmail.com

c Faculdades Pequeno Príncipe (FPP), Curitiba, PR, Brasil. Doutora em Ciências, e-mail: ceciliagarbelini@hotmail.com

d Faculdades Pequeno Príncipe (FPP), Curitiba, PR, Brasil. Doutora em Bioprocessos e Biotecnologias, e-mail: mrosaprado@hotmail.com

e Faculdades Pequeno Príncipe (FPP), Curitiba, PR, Brasil. Doutora em Sociologia, e-mail: leide.sanches@fpp.edu.br
} 
conforme análise de conteúdo de Bardin, por meio da qual se organizou e categorizou as informações contidas no conteúdo das entrevistas, as quais foram gravadas. Os resultados apontam que, embora não se trabalhe pontualmente com a questão do imigrante em sala de aula, a maioria $(90,3 \%)$ dos discentes tiveram contato com estes, inevitavelmente, em atividades práticas, seja por meio de atividades de estágio ou internato. Isso deflagra que nem sempre a teoria e a prática estão alinhadas, e, independentemente de cursos de graduação abordarem ou não a questão, os profissionais oriundos destes cursos terão que lidar com esta realidade em algum momento da vida, já que o fluxo migratório faz parte da realidade. As informações obtidas neste estudo permitiram averiguar junto aos discentes a importância de estar discutindo o tema dos imigrantes nas universidades, para o aprimoramento das práticas de acolhimento ao imigrante. Isto proporcionará aos discentes prestar um atendimento humanizado e solidário e um cuidado mais assertivo, além de formar egressos com uma visão humanística em relação aos imigrantes, dentro do contexto de um mundo cada vez mais globalizado.

Palavras-chave: Imigrantes. Solidariedade. Ensino em Saúde.

\section{Abstract}

Immigration is a phenomenon that implies challenges for both immigrants and their host societies. This study aimed to understand how the reception of immigrants is worked in undergraduate health courses, from the perspective of students. It is a descriptive exploratory qualitative study, which was carried out semi-structured interviews with twenty-eight (28) students with three (3) graduate courses in health two Higher Education Institutions (HEIS) in Curitiba / PR. The information was analyzed according to Bardin's content analysis, which organized and categorized the information contained in the content of the interviews, which were recorded. The results show that, although the issue of immigrants in the classroom is not dealt with punctually, the majority (90.3\%) of the students inevitably had contact with them in practical activities, either through internship or internship activities. This means that theory and practice are not always aligned, and regardless of whether undergraduate courses address the issue or not, practitioners from these courses will have to deal with this reality at some point in life, as the migratory flow is part of reality. The information obtained in this study allowed us to ascertain with students the importance of discussing the theme of immigrants in universities, to improve the practices of welcoming immigrants. This will provide students with humane and supportive care and more assertive care, as well as graduating graduates with a humanistic view of immigrants within the context of an increasingly globalized world.

Keywords: Immigrants. Solidarity. Health Teaching. 


\section{Introdução}

O mundo viu estarrecido em 2014, nas principais mídias jornalísticas, o drama no qual refugiados e migrantes chegavam à costa da Itália e da Grécia, em botes ou em embarcações precárias, abandonados à própria sorte. Nas principais mídias e jornais televisivos, via-se o desespero das pessoas em busca de um lugar para recomeçar suas vidas. Vidas essas que foram abandonadas nos seus países de origem devido às guerras, às perseguições políticas, étnicas, religiosas e à pobreza. Olhou-se com perplexidade o desespero das pessoas ao tentar chegar ao seu "El dourado", em vão, pois ao se lançarem ao Mar Mediterrâneo, muitas morreram afogadas, ou seus botes e algumas embarcações naufragaram. Outras pessoas, ao chegarem nas encostas morreram de hipotermia, como aconteceu com o menino Aylan Kurdi', cuja imagem de seu corpo em uma praia da Turquia chocou o mundo. Nessa crise humanitária muitas vidas se perderam e muitos sonhos foram interrompidos (PRADO, 2014).

Ocorre que, imigrantes e refugiados, pessoas que fogem da brutalidade das guerras e despotismos, da fome, e vem bater à porta e buscar ajuda, tem sido, não raramente, consideradas estranhas, desconhecidas e responsáveis por situações e ambivalências sobre as quais há inúmeras e históricas causas. Isso encaminha para o aumento da xenofobia e do racismo, bem como do número de representantes políticos destes segmentos, com projetos de confinamento e exclusão dos considerados indesejáveis. Um precariado emergente, formado por pessoas que receiam perder seus bens, suas posições sociais e seus empregos, passa a endossar tais ideologias e reafirmar a segregação dos considerados estrangeiros (BAUMAN, 2017).

Não obstante a mobilidade humana ser um fenômeno histórico que acompanha o desenvolvimento das sociedades e a crescente globalização, nas últimas duas décadas, os fluxos migratórios tornaram-se um fenômeno mundial crescente. Os deslocamentos forçados de pessoas, passaram de 33,9

\footnotetext{
1 Sobre o menino Aylan Kurdi, ver publicação no IHU, da UNISINOS. Cf. <http://www.ihu.unisinos.br/169-noticias/noticias-2015/546401-o-nome-dele-era-aylan-kurdie-tinha-apenas-3-anos-de-idade>.
} 
milhões em 1997 para 68,5 milhões em 2017, segundo dados do Alto Comissariado das Nações Unidas para Refugiados (ACNUR) (UN, 2018). Percebe-se por estes dados que o número de migrantes duplicou nas últimas duas décadas.

Pelos dados da ACNUR, o ano de 2018 teve um número de refugiados até então nunca visto no mundo. Nem mesmo no pós Segunda Guerra Mundial, em relação aos deslocamentos forçados das populações afetadas por este evento, estes dados se equiparam. As principais consequências deste deslocamento são as perseguições raciais, religiosas e políticas, os conflitos armados ou a violência generalizada, catástrofes naturais e a pobreza. Estas situações fazem com que estas populações se desloquem de seus países de origem, em busca de novas oportunidades em outros países, ou em determinadas situações apenas a outras regiões de seus próprios países (UN, 2019).

O movimento mundial de pessoas se deslocando de sua terra natal, seja por fluxos internos ou externos, é um problema que, inevitavelmente afeta todos, o que não é diferente no Brasil, onde, segundo dados do Comitê Nacional para os Refugiados (CONARE), há o acumulado de 10.145 refugiados reconhecidos, e 86.007 solicitações de reconhecimento de refugiados em tramitação. Nos últimos sete anos o Brasil recebeu 126.102 solicitações de reconhecimento de refugiados (CONARE, 2016; BRASIL, 2017).

A partir dos números levantados, evidencia-se que a configuração de espaços de sociabilidade em algumas cidades brasileiras está relacionada com o fluxo migratório, que movimenta os cidadãos a nível global. Tomás (2017) aponta que, um dos domínios onde se pode verificar as transformações trazidas por estes fluxos, é o das crenças e espiritualidade.

Nesse sentido, destacam-se lideranças religiosas, como O Papa Francisco, que apresentam a necessidade de acolhimento aos migrantes, considerando diversos fatores que os vulnerabilizam. A experiência do Papa Francisco com refugiados e imigrantes leva-o a enfatizar que as pessoas saem machucadas de suas terras, abandonam tudo na esperança de abrigo e proteção. No entanto, o que encontram na maioria das vezes é discriminação e preconceito, ao que ele chama de atitude de "globalização da indiferença". 
O episódio de Lampedusa ${ }^{2}$ é um dado marcante no ministério do Papa Francisco e o leva a tomar atitudes mais críticas frente à causa social e na defesa da vida humana. Em 2019, no dia mundial dos migrantes e refugiados, ele voltou a falar sobre este assunto, acusando a indiferença que traz morte e descarta pessoas. O que ele pede é acolhimento, que é o exercício da caridade que devolve a cada um o sentido de humanidade (FRANCISCO, 2013; 2019).

O exercício do acolhimento deve se dar em todos os âmbitos da vida humana. Assim, a partir da complexidade apresentada, no que tange a vida do imigrante em contexto brasileiro, especificamente neste estudo, busca-se identificar o acolhimento do imigrante no contexto de cursos de saúde, investigando como os estudantes da área de saúde percebem esta questão.

Dessa forma, o presente estudo se justifica por trazer à tona a necessidade da temática da saúde dos imigrantes no ensino da graduação da área da saúde, partindo-se da questão: Como os estudantes dos cursos de graduação em saúde percebem o acolhimento dos imigrantes?

\section{Trajetória da pesquisa}

Trata-se de um estudo exploratório descritivo com abordagem qualitativa, que permite ao pesquisador compreender a dinâmica interna de grupos, instituições e atores, procurando entender o fenômeno tal como ele ocorre, possibilitando formular questões, levantar problemas, aumentar a familiaridade do pesquisador com o ambiente, para que este possa modificar e clarificar conceitos. Pesquisas desse tipo podem expor os fatores que afetam a qualidade da assistência dos serviços de saúde, bem como contribuir para a formação e capacitação dos profissionais e buscar a melhoria da saúde da população (LAKATOS; MARCONI, 1991; COSTA; LOCKS; GIRONDI, 2015).

Este estudo foi realizado em duas Instituições de Ensino Superior (IES) dos cursos de Enfermagem, Medicina e Psicologia, da região de Curitiba/PR, pela conveniência de aproximação com os discentes destes cursos. Os

\footnotetext{
${ }^{2}$ No dia 8 de julho de 2013, no primeiro ano de seu Pontificado, Francisco viaja ate a ilha de Lampedusa, no sul da Itália, onde chegavam inúmeros imigrantes e refugiados em busca de vida e oportunidade.
} 
participantes do estudo foram vinte e oito (28) discentes, identificados pela letra $\mathrm{P}$, seguido pelos números de acordo com a sucessão das entrevistas ( $\mathrm{P} 1$, P2, P3...até P28), a fim de preservar a identidade dos mesmos. Dentre os entrevistados, 10 cursavam Enfermagem, 10 Medicina e 8 Psicologia, os quais, no momento da pesquisa, encontravam-se no sexto período de graduação de Enfermagem, no oitavo período de Medicina e no sétimo período de Psicologia, na modalidade seriada semestral.

A opção por procurar discentes dos últimos períodos ou ano dos respectivos cursos, se deu pela maior possibilidade destes já terem tido contato com imigrantes, seja em seus estágios ou internato.

A coleta das informações ocorreu entre agosto e novembro de 2018, por meio de entrevista semiestruturada, a partir de um formulário elaborado pelos pesquisadores com questões fechadas para caracterização do perfil dos participantes, e questões abertas sobre como a temática do imigrante estava sendo discutida no curso, quais as dificuldades na abordagem do imigrante no atendimento, quais os sentimentos emanados durante o atendimento e a visão do discente em relação ao imigrante. A pesquisa teve a aprovação do Comitê de Ética em Pesquisa sob número do Parecer 2.786.769.

A análise ocorreu e foi organizada em etapas: a pré-análise, a exploração do material e o tratamento dos resultados que compreende a inferência e a interpretação dos mesmos (BARDIN, 2016).

\section{Superando o Binarismo Social: nós e eles}

Quando perguntado aos discentes se a temática do imigrante havia sido discutida em seu curso, 11 responderam que sim e 17 responderam que não, demonstrando que as questões relativas ao imigrante têm sido discutidas, porém, é necessário ter um enfoque maior e de forma mais sistemática nos cursos de graduação da saúde.

Destes 11 discentes que tiveram a temática do imigrante discutida na universidade, 10 julgaram que os conteúdos desenvolvidos sobre imigrantes em determinadas disciplinas ajudaram ou ajudariam nas abordagens e aproximações com os imigrantes. As disciplinas que foram relatadas pelos discentes, em cujos espaços se discutiram essa temática foram Ciências Sociais 
(nos cursos de Medicina e Enfermagem) e Ética (no curso de Psicologia), além de um projeto de extensão de Saúde Coletiva no curso de Medicina.

Os participantes da pesquisa foram questionados se tiveram algum contato com imigrantes, e 14 destes responderam que esse contato ocorreu no estágio curricular, 7 responderam que foi no estágio extracurricular, 4 no trabalho, 3 no convívio social e 3 não tiveram contato com imigrantes.

Nota-se que os discentes têm um contato e uma abordagem maior com os imigrantes nos estágios curriculares e extracurriculares, o que denota uma procura dos imigrantes pelos serviços públicos de saúde, logo, esse dado demonstra a importância dessa temática ser discutida nos cursos de graduação da área da saúde.

As nacionalidades com as quais os estudantes tiveram contato, em sua maioria foram de haitianos, perfazendo $44,4 \%$ do total de discentes entrevistados, sendo venezuelanos e angolanos as nacionalidades de segundo maior contato.

Após o tratamento das informações obtidas pelas entrevistas com os participantes da pesquisa, obteve-se as unidades de registro e de significação, que possibilitaram evidenciar as categorias de análise, das quais optou-se por uma delas no presente artigo, sobre a percepção dos estudantes da área da saúde a respeito do acolhimento dos migrantes.

O conteúdo das falas dos participantes apresentou aspectos que revelaram suas percepções singulares sobre a temática dos imigrantes, trazendo o ponto de vista do discente e de sua própria interpretação sobre o tema.

Observou-se pela pesquisa que, embora não se trabalhe pontualmente com a questão do imigrante em sala de aula, a maioria (90,3\%) dos discentes tiveram contato com estes, inevitavelmente, em atividades práticas, seja por meio de atividades de estágio ou internato. Isso deflagra que nem sempre a teoria e a prática estão alinhadas, e, independentemente de cursos de graduação abordarem ou não a questão, os profissionais oriundos destes cursos terão que lidar com esta realidade em algum momento da vida, já que o fluxo migratório faz parte da realidade.

Isto porque a crise migratória é humana ou humanitária, uma vez que só existe pela relação que define e divide o mundo entre "nós e os outros", 
retificando um binarismo social que reflete um largo processo de construção, de exclusão e ausência de reconhecimento. Diante do cenário que reflete medidas restritivas aos direitos das populações migrantes, o que chama a atenção é o atual movimento de fechamento de portas, que aponta para a necessidade de ampliar o debate a partir da perspectiva dos direitos humanos (BAUMAN, 2017).

A análise de Bauman (2017, p. 7) sobre o que se convencionou chamar de "crise migratória", estabelece-se no plano investigativo que foca o fluxo migratório para a Europa, como uma grande tragédia que se abateu sobre as populações migrantes. Nesse processo migratório intenso, o autor reflete sobre os condicionantes psicológicos que abrem um flanco para o ódio, o medo e a rejeição, pelas populações europeias, quanto aos migrantes econômicos e refugiados de guerras, assim como aborda diversos ângulos das agruras e violações físicas e psicológicas a que estão sujeitas as populações migrantes no solo europeu "estranho".

A reflexão acima aplica-se em outras realidades, e os condicionantes psicológicos podem ser notados nas falas de alguns discentes, nas quais se deflagra os imigrantes como estranhos:

Inclusive foi uma situação, bem... complicada porque o médico que estava de plantão na hora, ele era totalmente contra imigrantes. Porque ela não falava nossa língua, só falava o francês. Então o contato de falar ali com a enfermeira e o médico era muito difícil. Ele dizia que não tinha obrigação de falar a língua dela, que ela estava no nosso país e que a total obrigação de saber a nossa língua era dela, que ela estava usando o nosso sistema de saúde, então tudo teria que vir dela, e ele como médico não precisaria fazer nada (P1, 2018).

Pela questão de ter sido um assalto... a pessoa roubou e foi agredida e por preconceito mesmo, de ser de outro país, de outra cultura totalmente diferente... não sabia a minha língua $[. .].(P 4,2018)$.

Percebe-se que há uma reação por parte dos participantes da pesquisa em relação ao preconceito e à ideia de que os imigrantes são concorrentes, embora sejam estrangeiros. 
Acho que o Brasil tem condição e muita condição de abrir a porta para dar campo de trabalho, estudo e crescimento para qualquer pessoa de qualquer lugar do mundo, aqui a gente tem muito campo fértil em todos os aspectos $(P 8,2018)$.

Só que o povo é difícil, eles acabam não sendo tão receptivos, e repetem: "ah! você vai tirar o meu trabalho, e não vou ter mais oportunidades". Nunca que eles tiram as oportunidades. Eu acho que não! Eu sei que no Brasil é difícil, demorei muito tempo pra encontrar um emprego, mas eu acredito que não (P9, 2018).

Para Simmel (1983), o contexto do estrangeiro na sociedade ocidental, é a mesma metrópole e o mesmo dinamismo do dinheiro, expressões da modernidade. Assim, o fato do estrangeiro estar exposto ao mesmo risco econômico e à mesma lógica de mercado (dinheiro), o torna concorrente vulnerável dentro do contexto social. Isso pode aproximá-lo, em uma relação de alteridade, mas também pode negá-lo, quando problematizadas sua liberdade e direitos, tornando esse estrangeiro ambivalente e contraditório no meio social.

Entretanto, notou-se pelas falas dos discentes participantes da pesquisa, que estes não demonstram aversão em relação aos imigrantes e buscam entender as causas que os levaram a vir para o Brasil.

Eu não concordo muito com essas posições, a partir de algumas experiências que eu tive de viagem, entendendo os outros países como eles recebem e se organizam. Uma pessoa falou para mim um dia, que nenhum imigrante quer sair do país dele, e saiba, se ele está saindo, é um sacrifício para ele. Tanto para nós que estamos os recebendo quanto para eles que estão saindo. Se eles pudessem a maioria não sairia (P3, 2018).

Diante disso, acredita-se que seja difícil, mas não é impossível, mesmo em sociedade competitiva, "reconstituir um senso comum, capaz de promover a solidariedade e, com ela, faculdades humanas mais elevadas, hoje tão massacradas no interior de nós mesmos", conforme indaga Oliveira (2013, p. 319).

Acredita-se que a concretização do acolhimento se dá por meio de ações e atitudes solidárias, de perceber o outro e suas dificuldades de inserção social.

Foi um aprendizado de ter empatia com eles, porque eu percebi que eles tem dificuldade para arranjar trabalho, eles arranjam subempregos, realmente foi um trabalho de empatia muito grande. De todos esses imigrantes haitianos que eu vejo, 
tem muita gente que tem preconceitos com eles pelo fato de serem negros, então comecei a ter empatia (P22, 2018).

Ah! Eu acho que por um lado, eu fico até feliz que venham e procuram a gente, mas por um lado é triste também porque eles têm de sair do país deles, por qualquer motivo que seja. Se for um motivo ruim e, se for bom, que bom que vieram (P6, 2018).

Evitar o diálogo provoca um silêncio que nasce da exclusão, do desinteresse e da globalização da indiferença. Abrir a porta aos que nela batem representa o início de um diálogo, necessário para compreender não apenas as realidades distantes, mas o mundo que todos em sociedade constroem diariamente, embora muitas vezes inconscientemente, por meio da ética do reconhecimento das diferenças.

[...] a gente não está preparado para atender o diferente. A gente não está nem preparado para atender o próprio surdo e mudo quando chega na Unidade. A gente sempre ou escreve, ou... muda o jeito de comunicação $[. .].(P 2,2018)$.

O Brasil é signatário dos principais tratados internacionais de Direitos Humanos e é parte da Convenção das Nações Unidas de 1951 sobre o Estatuto dos Refugiados e do seu Protocolo de 1967. O país promulgou a Lei n 9.474/97, adotando a definição ampliada de refugiado estabelecida na Declaração de Cartagena de 1984, que considera a "violação generalizada de direitos humanos" como uma das causas de reconhecimento da condição de refugiado (CONARE, 2016).

Nota-se em algumas falas que os participantes da pesquisa compreendem que a temática da migração é mais ampla, pois envolve os estrangeiros no Brasil e brasileiros em outros países.

Sou a favor! Tem tantos brasileiros que vão para outros lugares, porque não pode vir gente para cá também. Um monte de imigrantes brasileiros ilegais nos Estados Unidos, na Europa e agora outras nacionalidades não podem vir para o Brasil. Tem um pessoal que é contra e falam que não podem vir, mas eles não estão tirando o trabalho de ninguém. [...] Sou à favor, talvez atrapalhe em algum momento que eu não consigo me comunicar com alguém. Eles estão trabalhando, tudo certo! (P20, 2018). 
Devido ao novo processo migratório mundial, houve a necessidade de mudança na política migratória brasileira, sendo assim, foi sancionada em 2017 a Lei 13.445, que institui a Lei de Migração. O novo arcabouço legal representa um grande avanço no trato da questão migratória no Brasil e abre a perspectiva de esperança para os coletivos migrantes que já se encontram por aqui, para aqueles que estão por vir e para os brasileiros que emigraram para o exterior (OLIVEIRA, 2017). Esta consciência está presente entre os discentes, "Principalmente pelo momento que o nosso país está passando, que é o momento onde a gente está recebendo cada vez mais imigrantes e mais refugiados" (P3, 2018).

Segundo Oliveira (2017), o avanço mais geral reside na mudança de enfoque desse novo marco legal das migrações, agora com ênfase na garantia dos direitos do imigrante e estrangeiros que vierem a se estabelecer no Brasil. Os participantes da pesquisa parecem compreender esta exigência do momento: "Entender que se o país e o governo liberaram a entrada deles, eles têm que receber o atendimento como qualquer outro brasileiro" (P3, 2018). Ainda, "É importante! O Brasil é o país que mais acolhe imigrante na América do Sul é o que mais tem. E a gente não está preparado[...]” (P4, 2018).

Em relação ao estabelecimento de políticas voltadas à problemática da saúde dos imigrantes devem remeter ao Sistema Único de Saúde (SUS), que tem seus fundamentos, diretrizes e atribuições alicerçado na Constituição de 1988, na garantia de igualdade de direitos a todos os brasileiros e estrangeiros, incluindo a proteção e assistência à saúde, conforme consta nos artigos a seguir:

Art. 50 "Todos são iguais perante a lei, sem distinção de qualquer natureza, garantindo-se aos brasileiros e aos estrangeiros residentes no País a inviolabilidade do direito à vida, à liberdade, à igualdade, à segurança e à propriedade" (BRASIL, 1988).

Art. 60 "São direitos sociais a educação, a saúde, a alimentação, o trabalho, a moradia, o lazer, a segurança, a previdência social, a proteção à maternidade e à infância, a assistência aos desamparados, na forma desta Constituição" (BRASIL, 1988).

Art. $196^{\circ}$ "A saúde é direito de todos e dever do Estado, garantido mediante políticas sociais e econômicas que visem à redução do risco de doença e de outros agravos e ao acesso universal e igualitário às ações e serviços para sua promoção, proteção e recuperação" (BRASIL, 1988). 
Para que haja a garantia destes direitos para o imigrante, além de um conjunto de ações e serviços de saúde que prestem esse atendimento, tem que se pensar em como esses imigrantes serão atendidos na Atenção Primária à Saúde (APS). Isto porque a APS é a porta de entrada ao sistema de saúde e o local responsável pela organização do cuidado longitudinal à saúde dos indivíduos (BRASIL, 2007). Além destes atributos essenciais citados, a APS tem como atributos derivados: a orientação familiar, orientação comunitária e também a competência cultural dos profissionais (ASSIS et al., 2017).

Pergunta-se como está sendo prestado esse acolhimento, como estão sendo estabelecidos os vínculos e como está sendo atendido esse imigrante na APS. E o resultado da pesquisa aponta que este atendimento pode não estar sendo eficaz. É interessante observar que a carência da assistência está relacionada também com a carência na formação do profissional, conforme a fala a seguir:

\begin{abstract}
Então, o imigrante é mais um grupo que foi deixado de lado, porque querendo ou não, a nossa medicina é extremamente elitista e eles não estão formando a gente para saúde pública, por mais que as universidades falem isso. Eles estão formando a gente para ir para medicina privada e a medicina privada não cuida de imigrantes. Então a gente acaba não tendo esse contato mesmo e eu acho que não é interesse das universidades introduzir isso. Teria que ser uma luta para conseguir introduzir isso na grade curricular, mas eu acho importante sim, porque o médico ele não vai atender um grupo seleto de pessoas e vai chegar algum dia no consultório dele alguém que é imigrante. Vai ter uma coisa que ele não sabe e ele vai ter esse déficit, nesse vácuo no conhecimento dele que não vai ser preenchido, porque ele vai ter que entrar sozinho, entendeu?! (P22, 2018).
\end{abstract}

A última fala foi trazida propositadamente para este artigo, pois evidencia aspectos relacionados a atitudes de alguns profissionais de saúde, ligados à formação dos mesmos para as práticas em saúde. A reflexão do discente participante da pesquisa aponta para a necessidade de se trabalhar a problemática do imigrante ao longo de toda a formação de saúde. Isto porque, a figura do estrangeiro continua sendo um elemento marcante nos espaços de sociabilidade contemporâneos. Esta discussão não se encerra, pois o problema é cada vez mais acirrado na vida real, onde se produz estrangeiros em todos 
os lugares, porém, cada sociedade os produz de forma particular. Entretanto, não se pode esquecer que nenhum ser humano é ou pode ser considerado estrangeiro, pois se materializa e é real, mora muito próximo e é lembrado o tempo todo (BAUMANN, 2007).

\section{Considerações finais}

Esta pesquisa possibilitou perceber como a temática dos imigrantes é trabalhada nos cursos de graduação na área da saúde, pela perspectiva dos discentes.

Os resultados apontam que, embora não se trabalhe pontualmente com a questão do imigrante em sala de aula, a maioria (90,3\%) dos discentes tiveram contato com estes, inevitavelmente, em atividades práticas. Isto evidencia que o fluxo migratório faz parte da realidade e todos se depararão com esta em algum momento de suas vidas.

As informações obtidas neste estudo permitiram averiguar, junto aos discentes, a importância de se discutir o tema dos imigrantes nas universidades, para o aprimoramento das práticas de acolhimento ao imigrante. Isto proporciona aos discentes, futuros profissionais de saúde, prestar atendimento humanizado e solidário, bem como um cuidado mais assertivo, além de formar egressos com visão humanística de acolhimento aos imigrantes, dentro do contexto de um mundo cada vez mais globalizado.

Por fim, considera-se que o contato do discente com os imigrantes é cada vez maior, e nesse sentido, as temáticas relacionadas com a imigração precisam estar mais presentes no processo formativo, levando-se em consideração todos os aspectos da vida humana, como o religioso, o político, o étnico e o social.

\section{Referências}

ASSIS, N. M.; MARTINS, L. L.; SOUZA, L. M. M.; NICOLAO, I. A.; SOUZA, N. M. Acolhimento de imigrantes haitianos via integração ensino-serviço-pesquisa na atenção primária à saúde: relato de caso. Rev. bras. med. fam. Comunidade, Rio de 
Janeiro, v. 12, n. 39, p. 1-9, 2017. Disponível em: <https://www.rbmfc.org.br/rbmfc/article/view/1210>. Acesso em: 25 maio 2018.

BARDIN, L. Análise de conteúdo. Lisboa: Edições 70, 2016.

BAUMAN, Z. Tempos líquidos. Rio de Janeiro: Editora Zahar, 2007.

BAUMAN, Z. Estranhos à nossa porta. Trad. Carlos Alberto Medeiros. $1^{\mathrm{a}}$ ed. Rio de Janeiro: Zahar, 2017.

BRASIL. Constituição: República Federativa do Brasil. Brasília, DF: Senado Federal, 1988. Disponível em: <http://www.stf.jus.br/portal/constituicao> Acesso em: 29 jun. 2018.

BRASIL. Conselho Nacional de Secretários de Saúde - CONASS. Atenção Primária e Promoção da Saúde. Coleção Progestores: para entender a gestão do SUS. Brasília, 2007. p. 8-232. Disponível em: <http://bvsms.saude.gov.br/bvs/publicacoes/colec_progestores_livro8.pdf >. Acesso em: 25 jun. 2018.

BRASIL. Lei n 13.445, de 24 de maio de 2017. Institui a Lei de Migração. Diário Oficial da União, Brasília, DF, 25 maio 2017. Seção 1, p. 1. Disponível em: <https://legis.senado.leg.br/norma/17696552/publicacao/17696561>. Acesso em: 23 maio 2018.

CONARE. Conselho Nacional de Refugiados. Dados sobre refúgio no Brasil [Internet]. Brasília: CONARE, 2016. Disponível em:

$<$ http://www.acnur.org/portugues/recursos/estatisticas/dados-sobre-refugio-nobrasil/> Acesso em: 23 maio 2018.

COSTA, R.; LOCKS, M. O. H.; GIRONDI, J. B. R. Pesquisa exploratória descritiva In: LACERDA, M. R.; COSTENARO, R. G. S. Metodologias da pesquisa para a enfermagem e saúde, Porto Alegre, Moriá, p. 273-289, 2015.

FRANCISCO. Santa missa pelas vítimas dos naufrágios. Viagem à Lampedusa (Itália). 2013. Disponível em:

<http://www.vatican.va/content/francesco/pt/homilies/2013/documents/papafrancesco_20130708_omelia-lampedusa.html>. Acesso em: 15 nov. 2019.

FRANCISCO. Santa missa para o Dia Mundial do Migrante e do Refugiado. 2019. Disponível em:

<http://w2.vatican.va/content/francesco/pt/homilies/2019/documents/papafrancesco_20190929_omelia-migranti.html>. Acesso em: 15 nov. 2019.

LAKATOS, E. M.; MARCONI, M. A. Fundamentos de metodologia cientifica. São Paulo: Atlas, 1991.

OLIVEIRA, A. T. R. de. Nova lei brasileira de migração: avanços, desafios e ameaças. Rev. bras. estud. popul., São Paulo, v. 34, n. 1, p. 171-179, abr. 2017. Disponível em: 
<http://www.scielo.br/scielo.php?script=sci_arttext\&pid=S010230982017000100171> Acesso em: 27 maio 2018.

OLIVEIRA, P. de S. O processo de socialização e de solidariedade. Psicol. USP, São Paulo, v. 24, n. 2, p. 303-326, Aug. 2013.

Doi http://dx.doi.org/10.1590/S0103-65642013000200007

PRADO, L. C. A. Travessia clandestina: Itália bate recorde de imigração pelo mar. In: Folha de São Paulo, São Paulo, 2014. Disponível em:

<http://arte.folha.uol.com.br/mundo/2014/12/14/travessia-clandestina/>. Acesso em: 23 fev. 2019.

SIMMEL, G. O estrangeiro. In: MORAES FILHO. E. (Org.). Sociologia. São Paulo: Ática, 1983.

TOMÁS, M. I. Pluralidade Religiosa, Fluxos Migratórios e Cidadania. In: Os desafios da contemporaneidade ao cristianismo. Revista Lusófona de Ciência Das Religiões, n. 20, p. 459-481, 2017.

UN. United Nations. United Nations High Commissioner for Refugees. Global Trends Report: forced displacement in 2017. Geneva, 2018. Disponível em: <https://www.unhcr.org/statistics/unhcrstats/5b27be547/unhcr-global-trends2017.html> Acesso em : 24 set. 2018.

UN. United Nations High Commissioner for Refugees. Global Trends Report: forced displacement in 2018. Geneva, 2019. Disponível em: <https://www.unhcr.org/statistics/unhcrstats/5do8d7ee7/unhcr-global-trends2018.html> Acesso em : 20 jun. 2019. 